\title{
Latino adolescent substance use: A mediating model of inter- parental conflict, deviant peer associations, and parenting
}

\author{
Sergio B. Pereyra \\ Fresno State University \\ Roy A. Bean \\ Brigham Young University - Provo, roy_bean@byu.edu
}

Follow this and additional works at: https://scholarsarchive.byu.edu/facpub

Part of the Other Social and Behavioral Sciences Commons

\section{Original Publication Citation}

*Pereyra, S., \& Bean, R. A. (2017). Latino adolescent substance use: A mediating model of interparental conflict, deviant peer associations, and parenting behaviors. Children and Youth Services Review, 76, 154-162.

\section{BYU ScholarsArchive Citation}

Pereyra, Sergio B. and Bean, Roy A., "Latino adolescent substance use: A mediating model of interparental conflict, deviant peer associations, and parenting" (2017). Faculty Publications. 5035. https://scholarsarchive.byu.edu/facpub/5035 


\title{
Latino adolescent substance use: A mediating model of inter-parental conflict, deviant peer associations, and parenting
}

\author{
Sergio B. Pereyra ${ }^{\mathrm{a}, *}$, Roy A Bean ${ }^{\mathrm{b}}$ \\ a Department of Counselor Education and Rehabilitation in the Kremen School of Education at Fresno State University, Fresno, CA, United States \\ ${ }^{\mathrm{b}}$ Marriage and Family Therapy Program in School of Family Life at Brigham Young University, Provo, UT, United States
}

\section{A R T I C L E I N F O}

\section{Article history:}

Received 12 November 2016

Received in revised form 3 March 2017

Accepted 4 March 2017

Available online 10 March 2017

\section{Keywords:}

Latino adolescent

Substance use

Peer influence

Inter-parental conflict

Parenting

\begin{abstract}
A B S T R A C T
Substance use among Latino adolescents continues to be a growing concern for researchers and clinicians. This paper reviews relevant literature regarding the impact of inter-parental conflict (IPC), deviant peer associations (DPA) and parenting behaviors, namely as parental support, psychological control, and parental monitoring knowledge on substance use among Latino adolescents. Although mediating models of IPC and similar parenting behaviors on adolescent externalizing behaviors have been represented in empirical studies, none have included the influence of peer associations or have analyzed these factors with substance use among Latino adolescents in the U.S. This study investigated direct relationships of IPC and DPA with adolescent substance use, and tested parental support, psychological control and parental monitoring knowledge as mediators between those relationships in Latino adolescents. Structural equation modeling was used to analyze direct and indirect relationships of the variables mentioned among 744 Latino adolescents. Results indicated that DPA was positively associated with substance use, parental monitoring knowledge was negatively associated with substance use and that parental monitoring knowledge partially mediated the relationship between DPA and substance use. Implications of the findings are discussed in terms of areas of focus for interventions.
\end{abstract}

(c) 2017 Elsevier Ltd. All rights reserved.

\section{Introduction}

Substance use rates among the general population of U.S. adolescents have remained relatively stable since the 1990 's, however; there are several high-risk groups that continue to experience extreme difficulties and potential for later-life abuse (SAMHSA, 2006). Of particular concern are Latino youth as they have been found to have the highest prevalence of alcohol, tobacco, and other drug use in their lifetime when compared to other U.S. ethnic groups (Centers for Disease Control and Prevention, 2005; Telzer, Gonzales, \& Fuligni, 2014). Given high rates of substance use and the growth projections for Latinos, more investigation is warranted in order to identify the factors that influence substance use in this ethnic population.

Studying the topic of adolescent substance use, researchers have examined a number of intra- and extra-familial predictors including peer relationships, parental conflict and parenting behaviors (e.g., Fergusson, Swain, Nicola, \& Horwood, 2002; Bradford, Vaughn, \& Barber, 2008; Wills \& Cleary, 1996). In the case of Latinos, experts have suggested that family-level factors are especially salient (Falicov,

\footnotetext{
* Corresponding author.

E-mail address: spereyra@csufresno.edu (S.B. Pereyra).
}

2006) and, as such, numerous studies have tied family functioning to substance use in youth (e.g., Pokhrel, Unger, Wagner, Ritt-Olson, \& Sussman, 2008; Wong, 2008). In the models that have been tested, researchers have found both parenting behaviors and peer factors to be related to substance use in Latino adolescents (e.g., Pokhrel et al., 2008; Segura, Page, Neighbors, Nichols-Anderson, \& Gillaspy, 2003; Lopez et al., 2009).

Due to the consistent linking of parenting to substance use outcomes, researchers have moved beyond the simple examination of their influence as predictors and have begun to investigate parenting behaviors as mediators (e.g., Bradford et al., 2008). These studies represent more sophisticated conceptualizations of "spillover models" where family processes or other distal variables are examined for how they impact youth outcomes via various parenting factors (e.g., Benson, Buehler, \& Gerard, 2008). But given the robust and consistently-noted predictive power of peer influences on adolescent substance use in the literature (Lopez et al., 2009; Su \& Supple, 2014), it was deemed important to add peer influences to an analytical model to better account for the larger context. In an effort to bolster the limited knowledge regarding these processes in Latinos, this study examined the relationships among inter-parental conflict and deviant peer associations, as mediated by parenting behaviors, in relation to substance use among Latino youth. 


\section{Literature review}

\subsection{Theoretical foundation}

In efforts to adequately conceptualize the growing problem of adolescent substance use, Latino family researchers are increasingly utilizing systemic perspectives to frame their investigations (Frauenglass, Routh, Pantin, \& Mason, 1997; Lopez et al., 2009; Prado \& Pantin, 2011). In similar fashion, classic ecosystems theory substantiates the theoretical underpinnings of the current study (Bronfenbrenner, 1979, 1986), along with social learning theory (Bandura, 1977). These two theories have also been used in conjunction to describe the impact of family and peer relationships on Latino adolescent substance use in prior studies (e.g., Frauenglass et al., 1997). Specifically, the microsystem is the context in which parents and peers influence adolescent behavior, while social learning is the way in which this process transpires. Historically, the impact that parental modeling on children's drug use has been well documented (McDermott, 1984; Hawkins, Catalano, \& Miller, 1992), but more recent research also demonstrates how social learning occurs in social circles where peers are not only directly impacting adolescent drug use but also in attitudes and beliefs of drug use among Latino adolescents (Chalela, Velez, \& Ramirez, 2007).

In ecosystems theory, the microsystem includes individual contexts that have an impact on the adolescent, such as parenting endeavors and the adolescent's peer group (Bronfenbrenner, 1986). The mesosystem is comprised of interactions between influential people of the different contexts in which the adolescent is in direct contact with (Bronfenbrenner, 1986). Under this mesosystemic context, the current study evaluates the interaction between peer and parental systems, specifically the way in which parenting impacts peer relationships, which then the impacts Latino adolescent substance use. The other two subsystems of interest interacting with each other include the parental couple as specified by their level of conflict and the parent-child system as specified by parenting behaviors; the term "spillover" was introduced to the parenting literature more than two decades ago to describe this very process (Engfer, 1988).

The concept of "spillover effects" is also consistent with an ecological perspective and describes the exosystemic effect on the adolescent given that the marital couple relationship would be considered part of the exosystem since the adolescent is not part of that system but is still indirectly affected by couple conflict. Cox, Paley, and Harter (2001) describe spillover as transmissions of interaction patterns, affect and behavior from one relational setting to other relationships in the family. Theoretically, inter-parental conflict can place adolescents at risk for increased behavioral problems due to parents being overwhelmed by their own stress (Vandewater \& Lansford, 1998), becoming less responsive or supportive (Sturge-Apple, Davies, Boker, \& Cummings, 2004), or because they have less energy to invest in their parenting efforts. In the current study, the spillover effects of inter-parental relational conflict and deviant peer relationships are examined to assess their influence on adolescent substance use through key parenting behaviors.

\subsection{Inter-parental spillover model and adolescent behavioral problems}

Spillover theory continues to provide an adequate model for describing the process whereby inter-parental conflict interferes with good parenting practices, which can affect adolescent behavioral problems (Buehler, Benson, \& Gerard, 2006; Cox et al., 2001; Benson et al., 2008). As used here, inter-parental conflict is defined as harmful patterns of interaction between parents that are different from the typical disagreements that couples have (Buehler, Krishnakumar, Anthony, Tittsworth, \& Stone, 1994). The conflict can be categorized as either covert or overt in nature. Covert parental hostility refers to the type of parental interactions that are less direct (e.g., triangulation of children, passive-aggressive behaviors), while overt hostility is a manifestation of more direct parental interactions such as verbal criticism, yelling, and in some cases physical violence (Buehler et al., 1998).

Researchers have regularly found significant relationships between inter-parental conflict and adolescent maladaptive behaviors (e.g., Buehler \& Gerard, 2002). For example, Bradford et al. (2008) found that overt inter-parental conflict was directly associated with adolescent antisocial behavior. In a longitudinal study, marital conflict was also found to be related to parenting behaviors that, in turn, affected child maladjustment (Gerard, Krishnakumar, \& Buehler, 2006).

Research models of inter-parental conflict have included mediators to show how parental hostility can "spillover," influencing the parenting process which then influences adolescent behavioral problems. For example, one study showed a significant, indirect relationship between overt inter-parental conflict and antisocial behavior through parentchild conflict (Bradford et al., 2008). Benson et al. (2008) also found that acceptance and psychological intrusiveness, among other parental behaviors, mediated the relationship between inter-parental conflict and adolescent problem behavior. Similarly, Buehler et al. (2006) found that inter-parental hostility and adolescent externalizing problems was mediated by fathers' monitoring, mothers' psychological intrusiveness, and lower levels of parental acceptance. In a comparative study of adolescents and their families from nine countries (including one Latin-American nation, Colombia), Bradford et al. (2003) found direct and indirect associations between inter-parental conflict, parenting, and adolescent functioning. To date, however, inter-parental conflict has not been examined closely among U.S. Latinos to investigate the possibility that negative interactions between parents spillover and impact parenting behaviors, where they may ultimately contribute to negative outcomes such as adolescent substance use.

\subsection{Parenting behaviors and adolescent substance use}

Researchers have also found a number of parental factors that are associated with an increased risk of adolescent substance use, including the three key dimensions of parenting behavior studied here (i.e., support, psychological control, monitoring knowledge; Bean, Barber, \& Crane, 2006; Bradford et al., 2003). Parental support refers to the amount of love, acceptance, and closeness that an adolescent feels from their parents (Wills \& Cleary, 1996). Parental support has been associated with lower rates of adolescent substance use for low and high-risk adolescents (Wong, 2008). Similarly, Wills and Cleary (1996) found that increased parental support was associated with fewer risk factors and increased protective factors of substance use. Wang, Kim, Anderson, Chen, and Yan (2012), in their longitudinal study of the topic, found evidence of increased substance use as parental support decreased. One study with an ethnically diverse sample, a large portion of which were Latino (58\%), showed that parental support was significantly and negatively related to substance use (Ryan, Miller-Loessi, \& Nieri, 2007).

In important part of childrearing could include shaping a child's behavior to conform to societal norms, which is often manifested in a parent's desire to control or manage their children's behavior in order to prevent them from engaging in negative behavior. These efforts at control can usually be categorized as being either psychological or behavioral in nature. Barber (1996) describes psychological control as an attempt by parents to manipulate, invalidate and restrain the child's emotional and psychological experience. Much of the literature on psychological control frames it as a negative parenting behavior and it has found it be associated with negative outcomes in children (e.g., Rathert, Fite, \& Gaertner, 2011). Additionally, although no studies were found that linked parental psychological control with adolescent substance use, several studies were found that linked psychological control with negative externalizing behaviors, a common correlate of substance use (e.g., Pettit, Laird, Dodge, Bates, \& Criss, 2001; Arım \& Shapka, 2008; Rathert et al., 2011). The fairly limited body of literature is populated with some mixed findings as one study found that maternal psychological control predicted higher levels of externalizing 
behaviors in adolescents (Arım \& Shapka, 2008), while another (Bean et al., 2006) noted that psychological control (paternal and maternal) was not significantly related to delinquency. The influence of parental psychological control on Latino adolescents warrants a careful examination in order to clarify the mixed findings presented in the literature and to explore the relationships among a different ethnic (Latino) group.

Many parents attempt to regulate child behavior through parental knowledge, defined as the "awareness and information about a child's activities, whereabouts, and associations" (Tebes et al., 2011, p. 406). Although some researchers believe that this process of obtaining knowledge about the child's activities, environment and relationships come through the process of monitoring (Tebes et al., 2011; Lippold, Greenberg, \& Feinberg, 2011), which is also referred to as behavioral control (Kerr \& Stattin, 2000), Kerr, Stattin, and Özdemir (2012) recently argued that including parental knowledge in measures of monitoring can inflate associations between behavioral monitoring and adolescent adjustment. Parental knowledge in Latino research has also often been included in conceptualizations of monitoring (Yabiku et al., 2010; Coohey, Renner, \& Sabri, 2013), which has been significantly associated with less substance use among Latino adolescents (Yabiku et al., 2010). In order to stay consistent with updated research on behaviors associated with parental control (i.e., Kerr et al., 2012), this study utilized the term "monitoring knowledge," following Branstetter and Furman (2013).

\subsection{Deviant peer associations and adolescent substance use}

Adolescence is particularly marked by a strong peer influence and where peer pressure to engage in negative behaviors is heightened (Kornelis, Lindenberg, \& Veenstra, 2008). Adolescent peer group associations have been shown to be strong predictors of adolescent substance use, suggesting that an adolescent who affiliates himself/herself with other adolescents who smoke, drink or use drugs is more likely to use these same substances (Fergusson et al., 2002).

In considering the research literature, the association between peer behavior and youth self-reported substance use is no less evident among Latinos (e.g., Lopez et al., 2009). For example, Segura et al. (2003) found that higher peer alcohol use was significantly associated with higher rates of adolescent alcohol use. In another longitudinal study, peer influence was found to be the strongest predictor of current and life-time tobacco use among Latino adolescents, which found that peers had a greater influence on current tobacco use than on lifetime use (Chalela et al., 2007).

\subsection{Deviant peer associations and parenting behaviors}

Researchers have also highlighted the relationship between deviant peer associations (DPA) and parenting behaviors in relation to adolescent substance use, but there is less research on this topic for Latino adolescents. One study showed that family support reduced the influence of deviant peers on tobacco and marijuana use in Latino adolescents (Frauenglass et al., 1997). In this most recent literature search, a number of studies have found parenting behaviors to be predictive of peer deviance (O'Donnell, Richards, Pearce, \& Romero, 2012; Tompsett \& Toro, 2010), but no studies were found that tested the effects of DPA on parenting behaviors or mediating effects of parenting behaviors between DPA and adolescent behavioral problems.

As mentioned previously, the spillover model has been used to describe the effects that inter-parental conflict can have on the parenting process (Buehler et al., 2006; Benson et al., 2008) but in order to provide a more complete context, deviant peer associations are included in that mesosystemic interaction because of the tremendous impact that deviant peers have been shown to have on adolescent substance use (Kornelis et al., 2008; Fergusson et al., 2002), particularly among Latino youth (Lopez et al., 2009; Chalela et al., 2007; Segura et al., 2003). Furthermore, researchers have challenged the notion of unilateral effects between parents and children, giving support to the idea that adolescent behaviors (such as who they choose as their peers) can also have a significant influence on parenting behaviors (Huh, Tristan, Wade, \& Stice, 2006; Kerr et al., 2012). One of the main purposes of this study is to extend the concept of spillover effects to go beyond the typical marital conflict-to-parenting interaction and include the effects of poor adolescent choices regarding their peer spilling over to parenting practices in Latino families.

\subsection{Mediating models of parenting, peers and adolescent outcomes}

Researchers have regularly studied factors influencing parenting behaviors which, in turn, impact adolescent outcomes (e.g., McKinney, Milone, \& Renk, 2011) and spillover models of inter-parental conflict and parenting behaviors have been useful in explaining mediation effects of externalizing behavior in adolescents (e.g., Benson et al., 2008; Bradford et al., 2003; Krishnakumar \& Buehler, 2000); however, we are not aware of any studies that have examined a spillover model of interparental conflict and adolescent peer influence. There is a considerable body of literature describing interaction effects of parenting behaviors on adolescent peer relationships and maladaptive behaviors in adolescents (Henneberger, Tolan, Hipwell, \& Keenan, 2014; Crosnoe, Erickson, \& Dornbusch, 2002), but no studies were found that examined parenting behaviors as mediators in the relationship between parental conflict and adolescent substance use. In short, in order to be more consistent with an eco-systemic (Bronfenbrenner, 1979, 1986) and social learning (Bandura, 1977) framework, which has informed other empirically supported models of problems of substance use among Latino adolescents (Prado \& Pantin, 2011; Santisteban et al., 2003), this study sets out to examine more of the Latino adolescent's holistic experience of substance use by including deviant peer associations using a spillover approach patterned after previous studies (Benson et al., 2008; Buehler et al., 2006).

\section{Hypotheses}

The purpose of this study is to examine the associations between predictor variables of inter-parental conflict (IPC) and deviant peer associations (DPA), mediating parenting variables (parental support, psychological control and parental monitoring knowledge) and adolescent substance use among Latino adolescents while controlling for adolescent gender, age, socio-economic status, and parental structure. The following hypotheses are made:

H1. Both IPC and DPA will be positively associated with adolescent substance use.

H2. IPC will be negatively associated with both parental support and parental monitoring knowledge, and will be positively associated with psychological control.

H3. DPA will be negatively associated with parental support and will be positively associated with both psychological control and parental monitoring knowledge.

H4. Regarding parenting and substance use, both parental support and parental monitoring knowledge will be negatively associated with adolescent substance use, and psychological control will be positively related to adolescent substance use.

H5. In terms of mediation, all parenting behaviors will mediate the relationship between both predictor variables (IPC and DPA) and adolescent substance use.

\section{Method}

\subsection{Participants and procedure}

Data were obtained from the Youth and Family Project, a schoolbased, self-reported survey of 9-12th graders from a West Texas area 
school district. There were a total of 4150 students who were eligible to participate. Due to student absences and parental consent forms not being returned, 2292 students were surveyed, resulting in a $55.3 \%$ response rate. Due to questionable response integrity, 78 surveys were discarded, leaving a total of 2214 completed surveys. All students were recruited and surveyed in their designated English course (organized across the school district by grade level). Participants were monitored during the survey by graduate students, and high school and university faculty.

The Latino-focused sample consisted of 314 boys and 429 girls, with a final sample of 508 Latino youth from two-parent families, given the use of the inter-parental conflict variable. The mean age was 16, with a range of 14-18 years old. As for socio-economic status (SES), 19 (2.6\%) of them reported being "a lot poorer than most," 94 (12.6\%) reported being "a little poorer than most," 428 (57.5\%) reported being "about the same as most," 154 (20.7\%) reported being "a little richer than most," and 20 (2.7\%) of the participants reported being "a lot richer than most." As part of the decision-making process, it was determined that adolescents would not be able to accurately estimate their family's income in dollar amounts. This question was determined to be the best way to uncover subject's perception of their family-level income. The sample can be considered to be moderately-to-highly acculturated, based on: (a) participant enrollment in high school-level English courses (where they were surveyed), and (b) lower percentages of students with limited English proficiency in the school district (2.6\%, compared to $16.7 \%$ for the larger state).

\subsection{Measures}

\subsubsection{Inter-parental conflict (IPC)}

The inter-parental conflict variable (Cronbach's alpha $=0.88$ ) included a combination of items from the overt marital hostility scale (Cronbach's alpha $=0.87$ ) and covert marital hostility scale (Cronbach's alpha $=0.82$ ), which is an adolescent report of their parent's level of marital hostility (Buehler et al., 1994). The overt marital hostility scale consisted of 4 items measured on a four-point Likert scale ranging from "Never" to "Very Often." A sample from this scale reads, "My mother and father yell at each other." The covert marital hostility scale consisted of 4 items measured on a four-point Likert scale ranging from "Never" to "Very Often." A sample from this scale reads, "How often does one of your parents try to get you to side with one of them?" A confirmatory factor analysis was used to find the items that loaded appropriately on the scale as suggested by other studies using structural equation models (Xu, Zhang, \& Xia, 2007; Bean et al., 2006; Unger, Ritt-Olson, Soto, \& Baezconde-Garbanati, 2009) and all factor loadings were above 0.58 .

\subsubsection{Deviant peer associations (DPA)}

This scale (Cronbach's alpha $=0.90)$ contains items similar to these prior studies analyzing the influence of peers on adolescent behavior (e.g., Fergusson et al., 2002), and consisted of 11 items measured on a five-point Likert scale ranging from "none" to "all." A sample item from this scale reads, "Purposely damage or destroy property?," with all questions referring to the respondent's friend's behavior. After doing a CFA, three items were eliminated from the DPA scale because they did not load together with other items. All factor loadings that were included were above 0.52 .

\subsubsection{Parental support}

Parental support was measured using the 10-item Acceptance subscale from the revised Child Report of Parent Behavior Inventory (CRPBI; Barber, 1996). Parental support was differentiated into mothers' support (Cronbach's alpha $=0.92$ ) and fathers' support (Cronbach's alpha $=0.91$ ) as two separate latent variables. Adolescents responded on a 3-point Likert-type scale from $1=$ not like her (him) to $3=\mathrm{a}$ lot like her (him) as to how well items described their mothers and fathers. A sample item from this scale reads, "cheers me up when I am sad." CFA was used to identify the items that loaded appropriately onto the scale, all of which were above 0.68 for the mothers' support scale and above 0.75 for the fathers' support scale.

\subsubsection{Parental psychological control}

The variable (Barber, 1996) was also separated into mothers' psychological control (Cronbach's alpha $=0.72$ ) and fathers' psychological control (Cronbach's alpha $=0.71$ ). These constructs both consisted of 8 items measured on a three-point Likert scale ranging from "Not like her (him)" to "A lot like her (him)." A sample item from this scale reads, "often interrupts me." CFA was used to identify the items that loaded appropriately onto the scale and all factor loadings were above 0.57 for the mothers' psychological control scale and above 0.54 for the fathers' psychological control scale.

\subsubsection{Parental monitoring knowledge}

Monitoring knowledge was differentiated between mothers' monitoring knowledge (Cronbach's alpha $=0.82$ ) and fathers' monitoring knowledge (Cronbach's alpha $=0.88$ ) as well. The scales consisted of 5 items measured on a three-point Likert scale ranging from "doesn't know" to "knows a lot." Adolescents responded to how much their "parents really know" about items such as "who your friends are." CFA was used to identify the items that loaded appropriately onto scale, all of which were above 0.57 for the mothers' monitoring knowledge scale and above 0.67 for the fathers' monitoring knowledge scale.

\subsubsection{Adolescent substance use}

Rates of usage (in the past six months) were reported by adolescents for the following substances: alcohol, marijuana, hard drugs, and tobacco. Although there are a number of studies which use standardized measures of substance use (e.g., Branstetter \& Furman, 2013; Thompson \& Auslander, 2011), there are also many other studies which measure substance use in terms of frequency in a given time period, when combining a variety of substances to create one construct of substance use in adolescents as executed this study (Bertrand et al., 2013; Negriff \& Trickett, 2012; Chaoyang Li \& Chih-Ping, 2002). Answers from the respondents who reported a numeric value for the second question were recoded into four new scales. Recoding responses of substance use into scales is also documented in other studies (Daire, Turk, Johnson, \& Dominguez, 2013; Snedker, Herting, \& Walton, 2009), including ones focused on substance use among Latino adolescents (e.g., Buchanan \& Smokowski, 2009) All four of the new items were added to create the new Adolescent Substance Use scale (Cronbach's alpha $=0.68$ ). A confirmatory factor analyses indicated that all four items loaded onto the scale, with factor loadings all above 0.57 .

\subsection{Analysis}

Descriptive statistics are reported for all variables (see Table 1) and bivariate correlations are presented in Table 2. Initially, overt and covert marital hostility were conceptualized as separate factors, but preliminary analyses indicated that these scales were too highly correlated. Consequently, the eight items (four each) of overt and covert marital hostility were combined to create a single latent variable (inter-parental conflict). Structural equation modeling (Kline, 2010) was used to test the mediational model, which examined direct and indirect effects between the predictors (IPC and DPA) and the outcome variable of adolescent substance use, via the parenting behavior mediators.

Following Buehler et al.' (2006) approach, the analysis was conducted in three steps. A measurement model confirmed appropriate factor loadings for each latent variable (all loadings were above 0.52) and good model fit before proceeding to the structural path analysis portion. In order to test for mediation (Baron \& Kenny, 1986), the first step was to determine if there is a significant association between both predictor variables (IPC and DPA) and adolescent substance use in the initial 
Table 1

Means, SDs, and Ranges for observed variables.

\begin{tabular}{lllll}
\hline Latino adolescents & & & & \\
\hline & Min-Max & Range & Mean & SD \\
\hline Inter-parental conflict paternal & $5-20$ & 15 & 9.27 & 4.01 \\
Deviant peer associations & $5-25$ & 20 & 9.48 & 4.44 \\
Mother's support & $5-15$ & 10 & 11.99 & 2.94 \\
Father's support & $5-15$ & 10 & 11.08 & 3.27 \\
Mother's monitoring knowledge & $5-15$ & 10 & 12.07 & 2.65 \\
Father's monitoring knowledge & $5-15$ & 10 & 9.92 & 3.29 \\
Mother's psychological control & $5-15$ & 10 & 7.83 & 2.61 \\
Father's psychological control & $6-18$ & 12 & 9.41 & 2.97 \\
Adolescent substance use & $0-23$ & 23 & 5.70 & 5.13
\end{tabular}

structural model. Next, a model was estimated to include all three parenting constructs (support, psychological control, monitoring knowledge) as mediators. If the association between the predictors (IPC and DPA) and substance use is reduced, then partial mediation can be inferred, but if that association changes to be non-significant then full mediation can be inferred. Lastly, the indirect pathways from IPC and DPA to substance use are found to be significant through the parenting mediators. Indirect effects were also measured using the bootstrapping method to adjust for standard errors (Kline, 2010).

\section{Results}

Model fit statistics revealed a Chi-Square of 1772.998, $p<0.001$ $(\mathrm{df}=1064, N=671)$, a $\mathrm{CFI}=0.950, \mathrm{TLI}=0.945$, an RMSEA of 0.032 , and an SRMR of 0.046. Based on fit index standards, these results indicated that the model was a good fit for the data (i.e., CFI values above 0.95, RMSEA value below 0.05, SRMR value below 0.08; Hu \& Bentler, 1999). As can be seen in Fig. 1, deviant peer associations (DPA) had a significantly positive relationship with adolescent substance use $(\beta=$ $0.71, p<0.001$ ) and mothers' monitoring knowledge had a significantly negative relationship with adolescent substance use $(\beta=-0.13$, $p<0.05$ ). In terms of mothers' parenting, inter-parental conflict (IPC) was negatively associated with mothers' support $(\beta=-0.29$, $p<0.001$ ), but was positively associated with mothers' psychological control $(\beta=0.44, p<0.001)$. DPA was negatively associated with mothers' support $(\beta=-0.13, p<0.05)$ and with mothers' monitoring knowledge $(\beta=-0.38, p<0.001)$, but was positively associated with mothers' psychological control $(\beta=0.13, p<0.05)$. In terms of fathers' parenting, IPC was negatively associated with fathers' support ( $\beta=-0.27, p<0.001)$ and with fathers' monitoring knowledge $(\beta=-0.16, p=0.01)$, but was positively associated with fathers' psychological control $(\beta=0.41, p<0.001)$. DPA was negatively associated with fathers' monitoring knowledge $(\beta=-0.22, p<0.001)$.

In the analysis of indirect paths and mediation, 2000 bootstrap iterations were used and results indicated that mothers' monitoring knowledge was the only significant mediator in the model. Maternal monitoring knowledge mediated the relationship between DPA and substance use at the 0.05 level ( $p=0.035$ ), but the relationship between DPA and substance use did not change following the secondary analysis, which suggests only partial mediation between those relationships. As expected, males were more likely than females to engage in substance use $(p<0.05)$ and older adolescents were more likely to engage in substance use $(p<0.01)$. Surprisingly, this model accounted for $63 \%$ of the overall variance $\left(R^{2}\right)$ of adolescent substance use. All other paths (direct and indirect) were non-significant.

\section{Discussion}

\subsection{Effects of IPC and DPA on substance use}

The main focus of this study was to find out which factors influence substance use among Latino adolescents. The first hypothesis was partially supported in that deviant peer associations (DPA) were positively associated with substance use, but that inter-parental conflict did not significantly impact substance use. The finding on the positive relationship between peer influences and substance use among Latino youth is well documented in the literature (Segura et al., 2003; Chalela et al., 2007). While previous studies regarding Latino adolescent substance use have focused specifically on the relationship between peers' substance use (or the adolescent's perception of their peers' substance use) and that of the adolescent (e.g., Lopez et al., 2009; Segura et al., 2003), the current study provides evidence that the impact of peers on substance use among Latino adolescents extends beyond whether their friends engage in substance use or not. Results of this study suggest that Latino adolescents who associate more with peers who engage in deviant behavior (i.e., vandalism, aggressive behavior, gang involvement) are more likely to engage in substance use.

Surprisingly, there was no significant association found between inter-parental conflict (IPC) and substance use among the youth in this study. Although there are mixed findings regarding the role of compromised parenting (i.e., inter-parental conflict, Buehler et al., 2006), the results of this study were consistent with those that similarly found no significant associations between inter-parental conflict and children's maladjustment (Crockenberg \& Langrock, 2001; Frosch \& Mangelsdorf, 2001). However, it is important to distinguish between maladaptive or externalizing behavior in adolescents and the engagement in substance use. Although substance use can definitely be included under the general umbrella of externalizing behaviors, substance use is considered to be a more serious offense in that it leads to more serious consequences such as incarceration, disease, lifetime use and sexual deviance (e.g., Johnston, O'Malley, Bachman, \& Schulenberg, 2009; Centers for Disease Control \& Prevention, 2010). Fortunately for many Latino families, it seems that inter-parental conflict between the parental subsystem is not sufficiently detrimental enough to have a significant influence of adolescent substance use.

Table 2

Bivariate Correlations for observed variables in SEM model ${ }^{* * *}$.

\begin{tabular}{|c|c|c|c|c|c|c|c|c|c|}
\hline & 1 & 2 & 3 & 4 & 5 & 6 & 7 & 8 & 9 \\
\hline 1. Inter-parental conflict & - & & & & & & & & \\
\hline 2. Deviant peer associations & $0.279^{* *}$ & - & & & & & & & \\
\hline 3. Mother's support & $0.137^{* *}$ & 0.043 & - & & & & & & \\
\hline 4. Father's support & $0.385^{* *}$ & 0.017 & $0.076^{*}$ & - & & & & & \\
\hline 5. Mother's monitoring knowledge & $0.209^{* *}$ & $0.099^{* * *}$ & $0.446^{* *}$ & 0.064 & - & & & & \\
\hline 6. Father's monitoring knowledge & $0.394^{* *}$ & 0.071 & 0.002 & $0.678^{* *}$ & $0.217^{* *}$ & - & & & \\
\hline 7. Mother's psychological control & $0.125^{* *}$ & 0.038 & $0.777^{* *}$ & $0.085^{*}$ & $0.619^{* *}$ & $0.117^{* *}$ & - & & \\
\hline 8. Father's psychological control & $0.379^{* *}$ & 0.019 & $0.087^{*}$ & $0.965^{* *}$ & $0.157^{* *}$ & $0.699^{* * *}$ & $0.195^{* *}$ & - & \\
\hline 9. Adolescent substance use & $0.235^{* *}$ & $0.305^{* *}$ & $0.086^{*}$ & -0.003 & $0.167^{* *}$ & 0.049 & 0.071 & 0.016 & - \\
\hline
\end{tabular}

* $p<0.05$

** $p<0.01$.

*** $p<0.001$. 


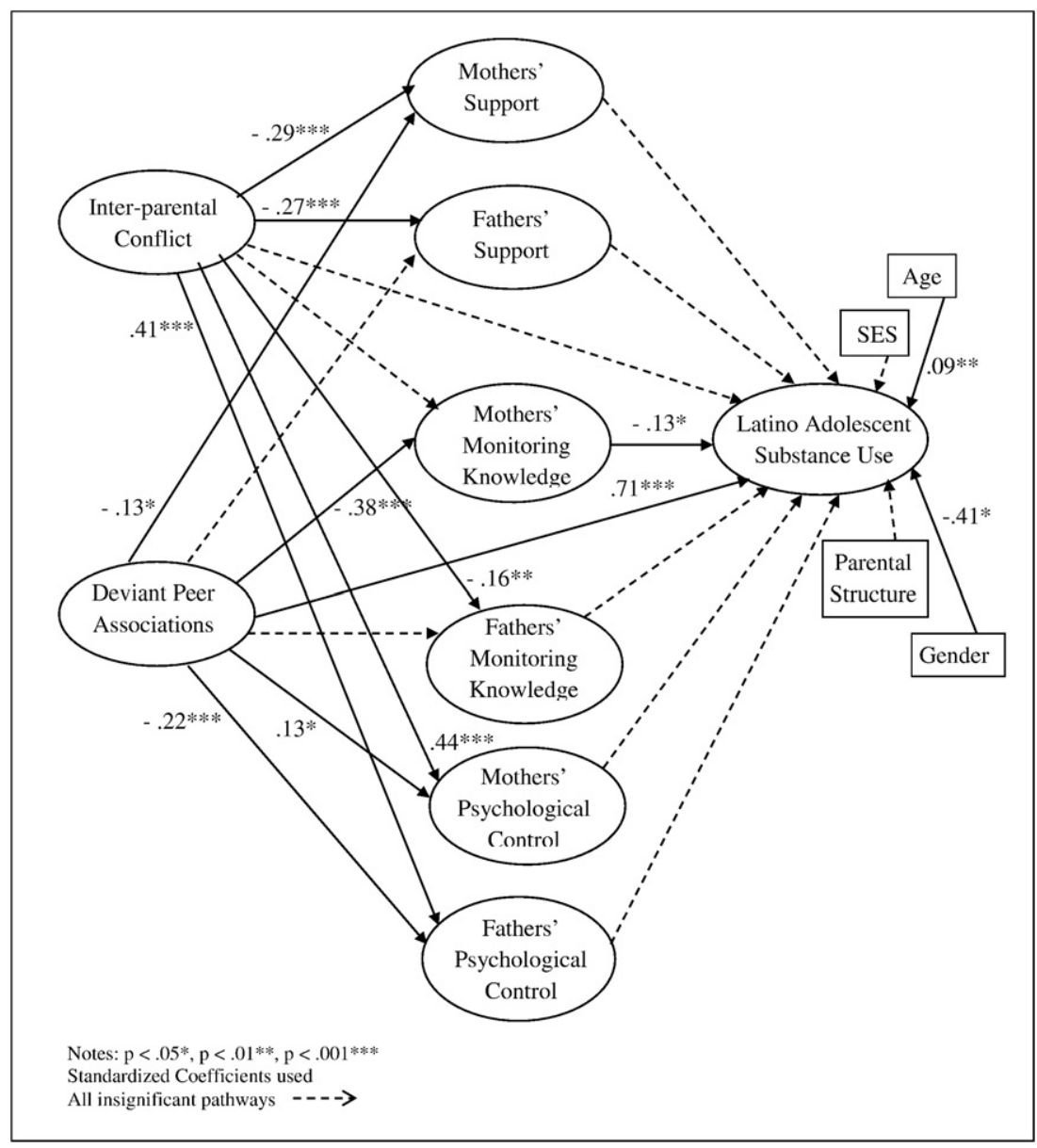

Fig. 1. Results Displayed on Final Path Model.

\subsection{Effects of IPC and DPA on parenting behaviors}

The second hypothesis regarding the effects of IPC on parenting behaviors of mothers and fathers was also partially supported. IPC was negatively associated with parental support (both mothers and fathers) and was positively associated with psychological control (maternal and paternal), but IPC was found to be significantly related to paternal monitoring knowledge only. Results regarding the relationships between IPC and parenting behaviors were found to be identical to those noted in previous studies (i.e., Buehler et al., 2006), with maternal monitoring knowledge being the only parenting behavior unrelated to IPC.

These findings, demonstrating the relationships between IPC and parenting in Latino families are particularly relevant due to the cultural aspects of family functioning. For example, Latino parents have been characterized as being more concerned with the wellbeing of their children than with the wellbeing of their marriage (e.g., Falicov, 2006), and with this focus they may realize how their marital conflict affects their ability to parent more effectively. Based on findings here, there is further support for the importance of addressing high levels of marital conflict among Latino couples even when they if they are primarily interested in parenting their children well.

The third hypothesis regarding the effects of deviant peer associations (DPA) and parenting behaviors was partially supported as well. DPA was negatively associated with both parents' monitoring knowledge, but was only negatively associated with mothers' support and positively associated with mothers' psychological control. Although some research suggests that contextual influences are more likely to affect fathers' parenting behaviors (Doherty, Kouneski, \& Erickson, 1998), these findings suggest that the impact of these influences on Latino parents depend on the context. The strength of the relationship between marital conflict and fathers' parenting behaviors were slightly greater than the relationship between marital conflict mothers' parenting behaviors, but the reverse was true for the relationships between DPA and maternal and paternal parenting behaviors.

Parenting behaviors have been shown to decrease the likelihood of adolescents associating with deviant peers (Durbin, Darling, Steinberg, \& Brown, 1993), which has been linked to substance use (Chassin, Pillow, Curran, Molina, \& Barrera, 1993), but the impact of deviant peer associations on parenting behaviors has been studied only rarely. A reciprocal effects model of child behavior impacting parenting was postulated in the 1970's (Sameroff, 1975) and only a handful of researchers have analyzed this model, but there is ample evidence of that reciprocal relationship (Huh et al., 2006; Kerr et al., 2012). When combined with past research regarding parenting and peer relationships (e.g., Durbin et al., 1993), the current study also supports a reciprocal effects model in that adolescents' peer associations can have an impact on parenting behaviors for Latino mothers and fathers. Although the effects of IPC and DPA on parenting behaviors was not the main focus of this study, this is an important contribution to the literature because of the emphasis that is placed on parenting in Latino cultural values (Falicov, 2006).

\subsection{Influence of parenting behaviors on substance use}

The fourth hypothesis regarding the influence of parenting behaviors on adolescent substance use was partially supported. Surprisingly, maternal monitoring knowledge was the only parenting behavior that was found to be significantly related, which is consistent with previous 
research findings (Branstetter \& Furman, 2013) and studies examining Latino families (Yabiku et al., 2010). Mixed findings have been noted in the literature previously in relationships between parenting and maladaptive youth behaviors between differing ethnic groups (e.g., Bean et al., 2006) and even among Latino adolescents (see Pokhrel et al., 2008; Smith \& Krohn, 1995). Specifically, past studies have regularly noted a relationship between parental support/warmth and substance use among ethnically diverse groups of adolescents (Wang et al., 2012; Ryan et al., 2007) and among Latinos specifically (Mogro-Wilson, 2008), but parental support was not found to have a significant impact on substance use here. We suggest that the introduction of DPA, which was found to have a very strong association with substance use, may be the reason for non-significance in pathways that have been found to be significant in other studies (e.g., Ryan et al., 2007). Similarly, in a study analyzing parenting and peer influence on substance use, Mayberry, Espelage, and Koenig (2009) found that parental support was not significant associated alcohol and marijuana use in their fixed effects model and that parental communication was not significantly associated with alcohol, marijuana or cigarette use in their random effects model, but found that peer influence was significantly associated with alcohol, marijuana and cigarette use in both models.

\subsection{Mediating effects of parenting behaviors on IPC and DPA}

Consistent with the spillover model (Cox et al., 2001), this study sought to apply Benson et al. (2008) and Buehler et al.'s (2006) approach to substance use among Latino adolescents with the inclusion of deviance peer associations (DPA) in the model. In this regard, the final hypothesis was partially supported in that maternal monitoring knowledge was found to partially mediate the relationship between DPA and substance use. This suggests that youth associations with deviant peers may influence their mothers' monitoring knowledge, which in turn can influence the adolescent's engagement in substance use. Results of this study are consistent with a confluence theoretical perspective of deviant peers bringing out the worst in each other (Dishion, Patterson, \& Griesler, 1994) while interacting with parenting behaviors to influence adolescent behavioral outcomes as suggested by Henneberger et al. (2014).

There are two possible interpretations for this phenomenon. First, peers might influence mothers' monitoring knowledge by diminishing her ability to monitor child. For example, deviant peers can entice these Latino adolescents to spend more time away from their families where they avoid the watch-care of their mothers, giving them free range to engage in unsupervised activities, including substance use. Another interpretation might consist of the mother's interpersonal processes. In the Latino culture, mothers take great pride in raising their children and for many Latina mothers childrearing becomes one of the most important endeavors (Falicov, 1982). A Latina mother might erroneously evaluate her child's engagement with deviant peers as a personal failure and might "throw in the towel" in regards to her monitoring efforts thereby increasing the likelihood of the child engaging in more substance use.

\section{Implications and suggestions for future research}

The significant direct and indirect effects found in this study can inform facilitators specifically working with Latino adolescents who are involved in substance abuse. Based on the current findings, we strongly encourage facilitators to place more emphasis on maternal monitoring knowledge and peer associations. Many Latino scholars have engaged in efforts to reduce substance use specifically among Latino adolescents and many well-crafted protocols have been introduced into the clinical intervention literature (see Szapocznik, Hervis, \& Schwartz, 2003; Prado \& Pantin, 2011; Santisteban \& Mena, 2009).

The current study found that an increase in mothers' monitoring knowledge was associated with less adolescent substance use, that increased deviant peer associations (DPA) were related to more adolescent substance use and that mothers' monitoring knowledge partially mediated that relationship. While all three of the above mentioned protocols have a fair amount of empirical support, Prado and Pantin's (2011) "Familias Unidas" approach is not only theoretically consistent with an ecological framework, but it includes a specific goal that emphasizes the importance of parental monitoring of peers (as part of the mesosystemic intervention). It also includes a goal to educate the parents about the impact of peer relationships and includes strategies such as supervised peer activities, parental role plays and family therapy sessions (Prado \& Pantin, 2011).

One of the difficulties that many Latino families face, especially among recent immigrants, which can impact parenting is the decrease in parental involvement (voluntary or involuntary) due to extreme work conditions (Ku \& Matani, 2001). In an effort to stay sensitive to these family situations, when only one parent can make it to these "Familia Unidas" parenting sessions, one recommendation based on the findings of this study is that as long as the mother was the parent who attended the parenting session, it could still be profitable to the family to help reduce adolescent substance use, since her monitoring knowledge is significantly associated with the decrease of adolescent substance use. While these goals and strategies address the direct effects of parenting monitoring knowledge and the impact of peer relationships on adolescent substance use, other helpful recommendations can be made to address the mediating effect of mothers' monitoring knowledge on the relationship between DPA and adolescent substance use.

One such recommendation to clinicians and facilitators would be to educate the parents (especially mothers) about the relationship that deviant peers can have youth substance use. When mothers are aware that friendships (particularly deviant peers) can impact her level of knowledge about youth activities, they can take precautions to mitigate those effects or even prevent them. For example, a Latina mother who is tempted to self-blame (as mentioned above) could benefit from parenting models that address psychological issues relating to their parenting efforts or even participate in individual therapy if needed. While there are many good parenting modules and individual psychotherapeutic programs available, we recommend an intervention that is both empirically supported and culturally sensitive. Although there is some debate on this topic, a recent meta-analysis regarding culturally adapted research showed that culturally adapted treatments were more effective than non-adaptive treatments (Smith, Domenech Rodríguez, \& Bernal, 2011).

Additionally, a culturally sensitive clinician could take a strengthbased approach and reiterate positive Latino cultural values that can help protect her from this self-defeating process, such as helping her connect with the cultural value of "el amor de madre," which refers to the powerful force of a mother's love in Latino families (Falicov, 1982). While this concept was introduced very early in the Latino conceptual literature and receives very little attention from scholars when compared to other cultural values such as "familismo", "personalismo" and "respeto" (Calzada, Huang, Linares-Torres, Singh, \& Brotman, 2014; Guilamo-Ramos et al., 2007; Arcia, Reyes-Blanes, \& Vazquez-Montilla, 2000), it should not be considered outdated or underestimated. "El amor de madre" is still a prevalent Latino cultural value in many Latino families (Millán \& Chan, 1991; Andrés-Hyman, Ortiz, Añez, Paris, \& Davidson, 2006) and is definitely relevant to the findings of the current study.

In terms of future research, the current study provides a baseline from which many other studies can immerge to help Latino families with the growing problem of substance use and externalizing behavior among Latino youth. Since this study found significant gender differences among the parents, it would be important to find out how adolescent gender moderated effects of parenting behaviors, DPA and IPC on adolescent substance use. In staying consistent with an ecosystemic framework, it would be important to examine other systems relevant 
to adolescent substance use, such as the macrosystem, chronosystem and other microsystems. When incorporating a macrosystem in the study, researchers should not only incorporate youth cultural orientation (Updegraff, Umaña-Taylor, McHale, Wheeler, \& Perez-Brena, 2012) but also parental acculturation levels to test for acculturation discrepancies since there is documented empirical evidence that suggests that these discrepancies lead to an increased risk of adolescent substance use (e.g., Unger et al., 2009). Also by replicating the current study using a longitudinal design, the chronosystem is introduced. Finally, the inclusion of the school system as an additional microsystem would be a valuable addition given the academic disparities among Latino youth (Turcios-Cotto \& Milan, 2013; Lopez, 2009) and empirical evidence that suggests that adolescent-teacher relationships influence adolescent externalizing behavior (Wissink et al., 2014; Perra, Fletcher, Bonell, Higgins, \& McCrystal, 2012).

\section{Limitations and conclusion}

Although this study greatly contributes to the literature regarding Latino adolescent substance use, there are a few limitations and significant factors of Latino adolescent substance use missing in this study. One limitation of this study is the fact that substance use was measured via selfreport in school, which could be possibly be influenced by a desire to be perceived a certain way by peers. Another limitation is the lack of longitudinal data in this sample, which lessens the predictive power of the study. There were also a few other variables that have been found to influence substance use among Latino adolescents, which were not included in this study that could have impacted the model including perceived discrimination (Basáñez, Unger, Soto, Crano, \& Baezconde-Garbanati, 2013), the influence of internalizing and externalizing behaviors on substance use (Buchanan \& Smokowski, 2009), and other Latino specific cultural values (Soto et al., 2011). Finally, acculturation and cultural orientation were not directly measured in this study, which is another limitation given the significance of acculturation on Latino adolescent substance use (Pokhrel, Herzog, Sun, Rohrbach, \& Sussman, 2013) and the effects of cultural orientation on youth adjustment (Updegraff et al., 2012).

In summary, the findings of this study enhance the current understanding of the relationships between peer influence, inter-parental conflict (IPC), parenting and substance use among Latino adolescents. This study found that mothers' monitoring knowledge was associated with less substance use, that deviant peer associations (DPA) was associated with more substance use and that mothers' monitoring knowledge mediated the relationship between DPA and substance use among Latino adolescents after controlling for adolescent gender, age, socio-economic status, and parental structure. Apart from these findings, this study also showed that IPC was associated with less parental support, more parental psychological control, and less paternal monitoring knowledge and that DPA was associated with less maternal support, less parental monitoring knowledge, and more maternal psychological control. The results of this study suggest that interventions to reduce substance use among Latino adolescents should focus on improving mothers' monitoring knowledge of the adolescents' behavior and relationships, but more importantly, that interventions should include a prevalent focus on decreasing deviant peer associations.

\section{References}

Andrés-Hyman, R. C., Ortiz, J., Añez, L. M., Paris, M., \& Davidson, L. (2006). Culture and clinical practice: Recommendations for working with Puerto Ricans and other Latinas(os) in the United States. Professional Psychology: Research and Practice, 37(6), 694-701.

Arcia, E., Reyes-Blanes, M. E., \& Vazquez-Montilla, E. (2000). Constructions and reconstructions: Latino parents' values for children. Journal of Child and Family Studies, 9, 333-350.

Arım, R., \& Shapka, J. (2008). The impact of pubertal timing and parental control on adolescent problem behaviors. Journal of Youth and Adolescence, 37(4), 445-455.

Bandura, A. (1977). Social learning theory. Englewood Cliffs, NJ: Prentice-Hall.

Barber, B. K. (1996). Parental psychological control: Revisiting a neglected construct. Child Development, 67(6), 3296-3319.
Baron, R. M., \& Kenny, D. A. (1986). The moderator-mediator variable distinction in social psychological research: Conceptual, strategic, and statistical considerations. Journal of Personality and Social Psychology, 51(6), 1173-1182.

Basáñez, T., Unger, J. B., Soto, D., Crano, W., \& Baezconde-Garbanati, L. (2013). Perceived discrimination as a risk factor for depressive symptoms and substance use among Hispanic adolescents in Los Angeles. Ethnicity \& Health, 18(3), 244-261.

Bean, R. A., Barber, B. K., \& Crane, R. D. (2006). Parental support, parental knowledge, and psychological control among African American youth. Journal of Family Issues, 27(10), 1335-1355.

Benson, M. J., Buehler, C., \& Gerard, J. M. (2008). Interparental hostility and early adolescent problem behavior: Spillover via maternal acceptance, harshness, inconsistency, and intrusiveness. Journal of Early Adolescence, 28(3), 428-454.

Bertrand, K., Richer, I., Brunelle, N., Beaudoin, I., Lemieux, A., \& Ménard, J. (2013). Substance abuse treatment for adolescents: How are family factors related to substance use change? Journal of Psychoactive Drugs, 45(1), 28-38.

Bradford, K., Barber, B. K., Olsen, J. A., Maughan, S. L., Erickson, L. D., Ward, D., \& Stolz, H. E. (2003). A multi-national study of interparental conflict, parenting, and adolescent functioning: South Africa, Bangladesh, China, India, Bosnia, Germany, Palestine, Colombia, and the United States. Marriage E' Family Review, 35(3/4), 107-137.

Bradford, K., Vaughn, L. B., \& Barber, B. K. (2008). When there is conflict: Interparental conflict, parent-child conflict, and youth problem behaviors. Journal of Family Issues, 29(6), 780-805.

Branstetter, S., \& Furman, W. (2013). Buffering effect of parental monitoring knowledge and parent-adolescent relationships on consequences of adolescent substance use. Journal of Child and Family Studies, 22(2), 192-198.

Bronfenbrenner, U. (1979). Contexts of child rearing: Problems and prospects. American Psychologist, 34, 844-850.

Bronfenbrenner, U. (1986). Ecology of the family as a context for human development: Research prospectives. Developmental Psychology, 22, 723-742.

Buchanan, R. L., \& Smokowski, P. R. (2009). Pathways from acculturation stress to substance use among Latino adolescents. Substance Use E Misuse, 44(5), 740-762.

Buehler, C., Krishnakumar, A., Anthony, C., Tittsworth, S., \& Stone, G. (1994). Hostile interparental conflict and youth maladjustment (Special issue: Family processes and child and adolescent development). Family Relations: An Interdisciplinary Journal of Applied Family Studies, 43(4), 409-416.

Buehler, C., Krishnakumar, A., Stone, G., Anthony, C., Pemberton, S., \& Barber, B. (1998). Interparental conflict styles and youth problem behaviors: A two-sample replication study. Journal of Marriage and Family, 60, 119-132.

Buehler, C., \& Gerard, J. M. (2002). Marital conflict, ineffective parenting, and children's and adolescents' maladjustment. Journal of Marriage and Family, 64, 78-92.

Buehler, C., Benson, M. J., \& Gerard, J. M. (2006). Interparental hostility and early adolescent problem behavior: The mediating role of specific aspects of parenting. Journal of Research on Adolescence, 16(2), 265-292 (Blackwell Publishing Limited).

Calzada, E. J., Huang, K., Linares-Torres, H., Singh, S. D., \& Brotman, L. (2014). Maternal familismo and early childhood functioning in Mexican and Dominican immigrant families. Journal of Latina/o Psychology, 2(3), 156-171.

Centers for Disease Control and Prevention (2005). Youth risk behavioral surveillance survey, youth online: Comprehensive results. Retrieved from http://apps.nccd.cdc.gov/ yrbss/

Centers for Disease Control and Prevention (2010). HIV surveillance report 2008. Vol. 20. Retrieved from http://www.cdc.gov/hiv/topics/surveillance/resources/reports/

Chalela, P., Velez, L. F., \& Ramirez, A. G. (2007). Social influences, and attitudes and beliefs associated with smoking among border Latino youth. Journal of School Health, 77(4), 187-195.

Chassin, L., Pillow, D. R., Curran, P. J., Molina, B. S. G., \& Barrera, M. (1993). Relation of parental alcoholism to early adolescent substance use: A test of three mediating mechanisms. Journal of Abnormal Psychology, 100, 449-463.

Chaoyang Li, M. A. P., \& Chih-Ping, C. (2002). Parental substance use as a modifier of adolescent substance use risk. Addiction, 97(12), 1537.

Coohey, C., Renner, L. M., \& Sabri, B. (2013). Victimization, parenting, and externalizing behavior among Latino and White adolescents. Journal of Family Violence, 28(4), 359-368.

Cox, M., Paley, B., \& Harter, K. (2001). Interparental conflict and parent-child relationships. In J. H. Grych, \& F. D. Fincham (Eds.), Interparental conflict and child development: Theory, research, and application (pp. 249-272). Cambridge, UK: Cambridge University Press.

Crockenberg, S., \& Langrock, A. (2001). The role of emotion and emotional regulation in children's responses to interparental conflict. In J. H. Grych, \& F. D. Fincham (Eds.), Interparental conflict and child development: Theory, research, and application (pp. 129-156). New York: Cambridge University Press.

Crosnoe, R., Erickson, K. G., \& Dornbusch, S. M. (2002). Protective functions of family relationships and school factors on the deviant behavior or adolescent boys and girls: Reducing the impact of risky friendships. Youth \& Society, 33, 515-544.

Daire, A. P., Turk, J., Johnson, J. M., \& Dominguez, V. (2013). Parental bonding and its effect on adolescent substance use and sexual debut. Adultspan Journal, 12(1), 54-64.

Dishion, T. J., Patterson, G. R., \& Griesler, P. C. (1994). Peer adaptations in the development of antisocial behavior. Aggressive behavior (pp. 61-95). US: Springer.

Doherty, W. J., Kouneski, E. F., \& Erickson, M. F. (1998). Responsible fathering: An overview and conceptual framework. Journal of Marriage and the Family, 60, 277-292.

Durbin, D. L., Darling, N., Steinberg, L., \& Brown, B. B. (1993). Parenting style and peer group membership among European-American adolescents. Journal of Research on Adolescence, 3, 87-100.

Engfer, A. (1988). The interrelatedness of marriage and the mother-child relationship. In R. A. Hinde, \& J. Stevenson-Hinde (Eds.), Relationships within families: Mutual influences (pp. 104-118). Oxford, UK: Clarendon.

Falicov, C. J. (1982). Mexican families. In M. McGoldrick, J. K. Pearce, \& J. Giordano (Eds.), Ethnicity and family therapy. New York: Guilford Press. 
Falicov, C. J. (2006). Family organization: The safety net of close and extended kin. In R. L. Smith, \& R. E. Montilla (Eds.), Counseling and family therapy with Latino populations: Strategies that work (pp. 41-62). New York, NY: Routledge, Taylor \& Francis Group.

Fergusson, D. M., Swain, C., Nicola, R., \& Horwood, J. L. (2002). Deviant peer affiliations, crime and substance use: A fixed effects regression analysis. Journal of Abnormal Child Psychology, 30, 419-430.

Frauenglass, S., Routh, D. K., Pantin, H. M., \& Mason, C. A. (1997). Family support decreases influence of deviant peers on Hispanic adolescents' substance use. Journal of Clinical Child Psychology, 26(1), 15-23.

Frosch, C. A., \& Mangelsdorf, S. C. (2001). Marital behavior, parenting behavior, and multiple reports of preschoolers' behavior problems: Mediation or moderation? Developmental Psychology, 37(4), 502-519.

Gerard, J. M., Krishnakumar, A., \& Buehler, C. (2006). Marital conflict, parent-child relations, and youth maladjustment: A longitudinal investigation of spillover effects. Journal of Family Issues, 27(7), 951-975.

Guilamo-Ramos, V., Dittus, P., Jaccard, J., Johansson, M., Bouris, A., \& Acosta, N. (2007). Parenting practices among Dominican and Puerto Rican mothers. Social Work, 52(1), $17-30$.

Hawkins, J. D., Catalano, R. F., \& Miller, J. Y. (1992). Risk and protective factors for alcohol and other drug problems in adolescence and early childhood: Implications for substance abuse prevention. Psychological Bulletin, 112, 64-105.

Henneberger, A. K., Tolan, P. H., Hipwell, A. E., \& Keenan, K. (2014). Using a confluence approach to understand the influences of parents and peers. Criminal Justice and Behavior, 41(11), 1327-1337.

Hu, L. T., \& Bentler, P. M. (1999). Cutoff criteria for fit indexes in covariance structure analysis: conventional criteria versus new alternatives. Structural Equation Modeling, 6(1), $1-55$.

Huh, D., Tristan, J., Wade, E., \& Stice, E. (2006). Does problem behavior elicit poor parenting? A prospective study of adolescent girls. Journal of Adolescent Research, 21, 185-204.

Johnston, L. D., O'Malley, P. M., Bachman, J. G., \& Schulenberg, J. E. (2009). Monitoring the future national results on adolescent drug use: Overview of key findings, 2008 (NIH publication no. 08-6418) (pp. 70). Bethesda, MD: National Institute on Drug Abuse.

Kerr, M., \& Stattin, H. (2000). What parents know, how they know it, and several forms of adolescent adjustment: Further support for a reinterpretation of monitoring. Developmental Psychology, 36, 366-380.

Kerr, M., Stattin, H., \& Özdemir, M. (2012). Perceived parenting style and adolescent adjustment: Revisiting directions of effects and the role of parental knowledge. Developmental Psychology, 48(6), 1540-1553.

Kornelis, D. J., Lindenberg, S., \& Veenstra, R. (2008). Beyond the class norm: Bullying behavior of popular adolescents and its relation to peer acceptance and rejection. Journal of Abnormal Child Psychology, 36(8), 1289-1299.

Kline, R. B. (2010). Principles and practice of structural equation modeling (3rd ed.). New York: Guilford Press.

Krishnakumar, A., \& Buehler, C. (2000). Inerparental conflict and parenting behaviors: A meta-analytic review. Family Relations, 49, 25-44.

Ku, L., \& Matani, S. (2001). Left out: Immigrants' access to health care and insurance. Health Affairs, 20, 247-256.

Lippold, M., Greenberg, M., \& Feinberg, M. (2011). A dyadic approach to understanding the relationship of maternal knowledge of Youths' activities to Youths' problem behavior among rural adolescents. Journal of Youth and Adolescence, 40(9), 1178-1191.

Lopez, B., Wang, W., Schwartz, S. J., Prado, G., Huang, S., Brown, C. H., ... Szapocznik, J. (2009). School, family, and peer factors and their association with substance use in Hispanic adolescents. The Journal of Primary Prevention, 30(6), 622-641.

Lopez, M. H. (2009). Latinos and education: Explaining the attainment gap. Washington, DC: Pew Hispanic Center.

Mayberry, M. L., Espelage, D. L., \& Koenig, B. (2009). Multilevel modeling of direct effects and interactions of peers, parents, school, and community influences on adolescent substance use. Journal of Youth and Adolescence, 38, 1038-1049.

McDermott, D. (1984). The relationship of parental drug use and parent's attitude concerning adolescent drug use to adolescent drug use. Adolescence, 19, 89-97.

McKinney, C., Milone, M. C., \& Renk, K. (2011). Parenting and late adolescent emotional adjustment: Mediating effects of discipline and gender. Child Psychiatry and Human Development, 42(4), 463-481.

Millán, F., \& Chan, J. (1991). Group therapy with inner city Hispanic acting-out adolescent males: Some theoretical observations. Group, 15(2), 109-115.

Mogro-Wilson, C. (2008). The influence of parental warmth and control on Latino adolescent alcohol use. Hispanic Journal of Behavioral Sciences, 30(1), 89-105.

Negriff, S., \& Trickett, P. K. (2012). Peer substance use as a mediator between early pubertal timing and adolescent substance use: Longitudinal associations and moderating effect of maltreatment. Drug and Alcohol Dependence, 126(1/2), 95-101.

O'Donnell, P., Richards, M., Pearce, S., \& Romero, E. (2012). Gender differences in monitoring and deviant peers as predictors of delinquent behavior among low-income urban African American youth. Journal of Early Adolescence, 32(3), 431-459.

Perra, O., Fletcher, A., Bonell, C., Higgins, K., \& McCrystal, P. (2012). School-related predictors of smoking, drinking and drug use: Evidence from the Belfast youth development study. Journal of Adolescence, 35(2), 315-324.

Pettit, G. S., Laird, R. D., Dodge, K. A., Bates, J. E., \& Criss, M. M. (2001). Antecedents and behavior-problem outcomes of parental monitoring and psychological control in early adolescence. Child Development, 72, 583-598.

Pokhrel, P., Unger, J. B., Wagner, K. D., Ritt-Olson, A., \& Sussman, S. (2008). Effects of parental monitoring, parent-child communication, and Parents' expectation of the Child's acculturation on the substance use behaviors of urban, Hispanic adolescents. Journal of Ethnicity in Substance Abuse, 7(2), 200-213.

Pokhrel, P., Herzog, T. A., Sun, P., Rohrbach, L. A., \& Sussman, S. (2013). Acculturation, social self-control, and substance use among Hispanic adolescents. Psychology of Addictive Behaviors, 27(3), 674-686.
Prado, G., \& Pantin, H. (2011). Reducing substance use and HIV health disparities among Hispanic youth in the USA: The Familias Unidas program of research. Psychosocial Intervention, 20(1), 63-73.

Rathert, J., Fite, P., \& Gaertner, A. (2011). Associations between effortful control, psychological control and proactive and reactive aggression. Child Psychiatry and Human Development, 42(5), 609-621.

Ryan, L. G., Miller-Loessi, K., \& Nieri, T. (2007). Relationships with adults as predictors of substance use, gang involvement, and threats to safety among disadvantaged urban high-school adolescents. Journal of Community Psychology, 35(8), 1053-1071.

Sameroff, A. (1975). Early influences on development: Fact or fancy? Merrill-Palmer Quarterly, 21, 263-294.

Santisteban, D. A., Coatsworth, D., Perez-Vidal, A., Kurtines, W. M., Schwartz, S. J., \& Laperriere, A. (2003). Efficacy of brief strategic family therapy in modifying Hispanic adolescent behavior problems and substance use. Journal of Family Psychology, 17 121-133.

Santisteban, D. A., \& Mena, M. P. (2009). Culturally informed and flexible family-based treatment for adolescents: A tailored and integrative treatment for Hispanic youth. Family Process, 48(2), 253-268.

Segura, Y. L., Page, M. C., Neighbors, B. D., Nichols-Anderson, C., \& Gillaspy, S. (2003). The importance of peers in alcohol use among Latino adolescents: The role of alcohol expectancies and acculturation. Journal of Ethnicity in Substance Abuse, 2(3), 31-49.

Smith, C., \& Krohn, M. D. (1995). Delinquency and family life among male adolescents: The role of ethnicity. Journal of Youth and Adolescence, 24(1), 69-92.

Smith, T., Domenech Rodríguez, M., \& Bernal, G. (2011). Culture. Journal of Clinical Psychology, 67, 166-175.

Snedker, K. A., Herting, J. R., \& Walton, E. (2009). Contextual effects and adolescent substance use: Exploring the role of neighborhoods. Social Science Quarterly, 90(5) 1272-1297 (Blackwell Publishing Limited).

Soto, C., Unger, J. B., Ritt-Olson, A., Soto, D. W., Black, D. S., \& Baezconde-Garbanati, L (2011). Cultural values associated with substance use among Hispanic adolescents in Southern California. Substance Use E Misuse, 46(10), 1223-1233.

Sturge-Apple, M. L., Davies, P. T., Boker, S. M., \& Cummings, E. M. (2004). Interparental discord and parenting: Testing the moderating roles of child and parent gender. Parenting: Science and Practice, 4, 361-380.

Su, J., \& Supple, A. (2014). Parental, peer, school, and neighborhood influences on adolescent substance use: Direct and indirect effects and ethnic variations. Journal of Ethnicity in Substance Abuse, 13(3), 227-246.

Substance Abuse and Mental Health Services Administration (SAMHSA) (2006). Results from the 2005 national survey on drug use and health: national findings. Rockville, MD: Office of Applied Studies (NSDUH series h-30, DHHS publication no. SMA 06-4194).

Szapocznik, J., Hervis, O., \& Schwartz, S. (2003). Brief strategic family therapy for adolescen drug abuse. Bethesda, Maryland: U. S. Department of Health and Human Services.

Tebes, J., Cook, E., Vanderploeg, J., Feinn, R., Chinman, M., Shepard, J., ... Connell, C. (2011) Parental knowledge and substance use among African American adolescents: Influence of gender and grade level. Journal of Child and Family Studies, 20(4), 406-413.

Telzer, E., Gonzales, N., \& Fuligni, A. (2014). Family obligation values and family assistance behaviors: Protective and risk factors for Mexican-American adolescents' substance use. Journal of Youth and Adolescence, 43(2), 270-283.

Thompson, R. G., Jr., \& Auslander, W. F. (2011). Substance use and mental health problems as predictors of HIV sexual risk behaviors among adolescents in foster care. Health $\mathcal{E}$ Social Work, 36(1), 33-43.

Tompsett, C. J., \& Toro, P. A. (2010). Predicting overt and covert antisocial behaviors: Parents, peers, and homelessness. Journal of Community Psychology, 38(4), 469-485.

Turcios-Cotto, V. Y., \& Milan, S. (2013). Racial/ethnic differences in the educational expectations of adolescents: Does pursuing higher education mean something different to Latino students compared to White and Black students? Journal of Youth and Adolescence, 42(9), 1399-1412.

Unger, J. B., Ritt-Olson, A., Soto, D. W., \& Baezconde-Garbanati, L. (2009). Parent-child acculturation discrepancies as a risk factor for substance use among Hispanic adolescents in Southern California. Journal of Immigrant and Minority Health, 11, 149-157.

Updegraff, K. A., Umaña-Taylor, A. J., McHale, S. M., Wheeler, L. A., \& Perez-Brena, N. J. (2012). Mexican-origin youth's cultural orientations and adjustment: Changes from early to late adolescence. Child Development, 83(5), 1655-1671.

Vandewater, E. A., \& Lansford, J. E. (1998). Influences of family structure and parental conflict on children's well-being. Family Relations, 47(4), 323-330.

Wang, Y., Kim, S., Anderson, E., Chen, A., \& Yan, N. (2012). Parent-child acculturation discrepancy, perceived parental knowledge, peer deviance, and adolescent delinquency in Chinese immigrant families. Journal of Youth and Adolescence, 41(7), 907-919.

Wills, T. A., \& Cleary, S. D. (1996). How are social support effects mediated? A test with parental support and adolescent substance use. Journal of Personality and Socia Psychology, 71(5), 937-952.

Wissink, I. B., Deković, M., Stams, G., Asscher, J. J., Rutten, E., \& Zijlstra, B. J. H. (2014) Moral orientation and relationships in school and adolescent pro- and antisocial behaviors: A multilevel study. The Journal of School Nursing, 30(3), 216-225.

Wong, M. M. (2008). Perceptions of parental involvement and autonomy support: Their relations with self-regulation, academic performance, substance use and resilience among adolescents. North American Journal of Psychology, 10(3), 497-518.

Xu, A., Zhang, J., \& Xia, Y. R. (2007). Impacts of parents' divorce on Chinese children: A mode with academic achievement as a mediator. Marriage E Family Review, 42(3), 91-119.

Yabiku, S. T., Marsiglia, F. F., Kulis, S., Parsai, M. B., Becerra, D., \& Del-Colle, M. (2010). Parental monitoring and changes in substance use among Latino/a and non-Latino/a preadolescents in the southwest. Substance Use \& Misuse, 45(14), 2524-2550. 